DOI 10.37882/2223-2982.2020.06-2.32

\title{
ЛАКУНАРНОСТЬ КАК ЛИНГВИСТИЧЕСКОЕ ЯВЛЕНИЕ: АНАЛИЗ АНГЛИЙСКИХ ТЕРМИНОВ ПРАВА, ОСНОВАННЫХ НА МЕТАФОРЕ
}

\section{LINGUISTIC LACUNARITY:THE ANALYSIS OF METAPHOR BASED LEGAL TERMS IN THE ENGLISH LANGUAGE}

\section{N. Tikhonova}

Summary: Basing on the typology of interlanguage lacunae, English legal metaphor based terms are considered; the ways of translating them into Russian are analyzed; the most frequent ways of translating terms of this type are highlighted; the reasons for the prevalence of specific translation methods are given.

Keywords: lacuna, lacunarity, translation, translation method.
$\mathrm{H}$ а сегодняшний день успешная карьера в юридической сфере в немалой степени зависит от уровня владения английским языком, поскольку знание языка дает возможность читать профессиональную литературу и периодику, общаться с иностранными коллегами, выступать на конференциях соответствующего профиля и т.д. Язык права непосредственно связан с государственной правовой системой, что является причиной сложностей определенного порядка. Так, возникают дополнительные трудности при переводе, когда переводчику зачастую необходимо не просто найти наиболее точный эквивалент для передачи того или иного понятия, но и провести исследование и выяснить, какова история термина, когда он начал употребляться, с чем было связано его появление, в рамках какой юридической системы он получил распространение.

В связи с этим особое внимание привлекают не имеющие прямого переводного эквивалента в русском языке юридические термины, образующие межъязыковые и межкультурные лакуны. Такие безэквивалентные лексические единицы, ответственные за постоянное расширение явления лакунарности, выражают национальные особенности правовой культуры. Это в первую очередь касается англоязычной юридической терминологии, поскольку в Великобритании и США правовая система - основанная на прецедентах система общего права существенно отличается от правовых систем других государств, где главенствующая роль принадлежит нормативному акту как основному источнику права.

Явление лакунарности впервые получило освещение
Тихонова Наталия Юрьевна

Аспирант, Московский государственный университет им. М.В. Ломоносова natatih1994@yandex.ru

Аннотация: На основе типологии межъязыковых лакун рассматриваются английские термины права, основанные на метафоре; анализируются способы их перевода на русский язык; выделяются наиболее частотные способы перевода терминов данного вида; приводятся причины преобладания конкретных способов перевода.

Ключевые слова: лакуна, лакунарность, перевод, способ перевода.

в работе канадских учёных Ж.П. Вине и Ж. Дарбелье [4, С. 10] в конце 1950-х гг. В СССР первыми из отечественных лингвистов проблему лакунарности рассматривали

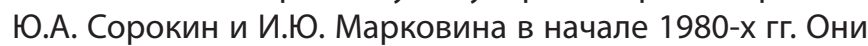
определили лакуны как «всё, что в инокультурном тексте реципиент не понимает, что является для него странным, требует интерпретации, служит сигналом присутствия в тексте национально-специфических элементов культуры, в которой создан текст» [3, С. 37].

На сегодняшний день одним из крупнейших отечественных специалистов в области лакунарности является Л.К. Байрамова, выделившая две группы факторов, которые влияют на появление лакунарных единиц: лингвистические факторы и факторы экстралингвистические. К лингвистическим факторам относятся несовпадение в развитии систем языков и своеобразие в членении объективного мира, тогда как экстралингвистические факторы включают в себя своеобразие менталитета, традиций и обычаев представителей разных культур, а также различия в социально-экономических условиях жизни [1, С. 51].

Англоязычные термины права, не имеющие прямых эквивалентов-соответствий в русском языке, но переводящиеся описательно и образующие лексические лакуны, могут классифицироваться и описываться различными способами в зависимости от того, что в наибольшей степени интересует исследователя - план содержания (здесь внимание сосредотачивается на явлениях полисемии, омонимии, синонимии, антонимии терминов) или план выражения (в частности вопросы словообра- 
зования, морфологического состава и синтаксических моделей терминов).

В данной статье будут рассмотрены английские юридические термины, основанные на метафоре, и варианты их перевода на русский язык при отсутствии прямого эквивалента. Проведение системного анализа ряда терминов обуславливает необходимость приложения к ним определенной классификации, иными словами, их обзор с точки зрения некой типологии. Наиболее целесообразным для описания английских метафорических терминов права, образующих лакуны, представляется применение типологии А.А. Махониной и М.А. Стерниной [2, С. 75-77]. В соответствии с данной типологией англо-русских межъязыковых лакун, все они подразделяются на две большие группы: обобщающие и конкретизирующие. Основанием для выделения обобщающих лакун служит отсутствие в исследуемом языке (в нашем случае в русском языке) соответствующего обобщения, тогда как конкретизирующие лакуны объединяет отсутствие в исследуемом языке соответствующей конкретизации по тому или иному известному признаку. Однако для более полного охвата и описания лексических единиц учеными была выдвинута еще одна категория обобщающе-конкретизирующие лакуны, определяемые на основании отсутствия в исследуемом языке одновременно как обобщения, так и конкретизации.

Итак, типология лакун А.А. Махониной и М.А. Стерниной дает возможность системно и полно рассмотреть английские термины права, основанные на метафоре. Анализ терминов из специализированных словарей (Oxford Dictionary of Law, Black's Law Dictionary) и словарей общего языка (Macmillan Dictionary, Oxford Advanced Learner's Dictionary) показал, что наиболее широко в рамках англо-русской метафорической терминологии права представлен тип конкретизирующих лакун, что, на наш взгляд, связано с общей тенденцией русского языка к конкретизации, когда лексические единицы в русском языке характеризуются большей семантической конкретностью, «узостью» (ср. meal - завтрак, обед, полдник, ужин). Перевод таких терминов в большинстве случаев осуществляется методом описательного перевода, поэтому на более конкретное значение русского термина указывает уже количество входящих в его состав лексических единиц. Такой описательный перевод иногда служит комментарием к переводу дословному, буквальному, или калькированному. Разницу в количестве словарных единиц и, как следствие, более конкретное значение терминов в русском языке можно проиллюстрировать следующими примерами:

naked trust - пассивная доверительная собственность; траст, по которому доверенное лицо не имеет активных обязанностей (термин на русском языке напрямую называет важнейший признак подразумеваемой собственности); knock and talk - метод ведения следствия, подразумевающий получение добровольного согласия граждан на проведение обыска в их частной собственности при отсутствии ордера на обыск (вследствие неприменения этой техники в отечественной следственной практике требуется подробное разъяснение условий ее осуществления);

fair wear and tear - допустимый износ и убыль основных средств (пара глаголов wear и tear переводится существительными износ и убыль с сохранением семантического ядра, прилагательному fair в переводе подобран прямой эквивалент, однако в русском варианте имеется уточняющий элемент, а именно указание на объект, об износе и убыли которого идет речь);

golden handshake - «золотое рукопожатие»; денежное вознаграждение с целью побуждения работника к досрочному уходу на пенсию (пожатие руки как метафора прощания, адъективный элемент golden как указание на щедрую компенсацию, а также добавление подробного разъяснения условий выплаты в русскоязычном терминологическом сочетании)

golden hello - «золотое приветствие»; большой аванс, предлагаемый ценному сотруднику при устройстве на новое рабочее место (приветствие как метафора желания взять сотрудника на работу, адъективный элемент golden как указание на крупную разовую выплату, а также, как и в предыдущем примере, добавление детального разъяснения условий выплаты в русскоязычном термине);

knock for knock - «удар за удар»; применяемый при страховании автомобилей принцип индивидуальной ответственности страховщиков (здесь следует подробно пояснить содержание данной практики, поэтому описательный перевод необходим);

unless order - условное решение суда, лишающее обвиняемого права на защиту (если бы не описательный перевод, конкретизирующий данный правовой феномен, термин скорее можно было бы трактовать как нормативный акт, вступающий в силу при неисполнении стороной определенных обязательств).

Обобщающие лакуны встречаются намного реже и обычно образуются при переводе наименований различных законов, законодательных актов, нормативных принципов. Носителю русского языка необходимо пояснить, какого рода феномены в целом стоят за терминологической единицей, какие явления относятся к обозначенному метафорическим термином правовому концепту. Это можно видеть на примерах, где преобладающим методом перевода также является описательный перевод, иногда служащий комментарием к переводу дословному, буквальному, или калькированному, а также переводу трансформационному, где главную роль играют разнообразные синтаксические трансформации (различия в предложном управлении, видах словосочетаний и т.д.): 
eggshell skull rule - принцип ответственности за ущерб, независимо от тяжести последствий (здесь под eggshell skull следует понимать любые факторы, связанные с состоянием здоровья потерпевшего или жертвы, например, особенность строения тела, чувствительность, болезнь, которые не могут служить в качестве смягчающего обстоятельства при вынесении приговора преступнику [9]);

Brady violation - нарушение уголовного процесса стороной обвинения, связанное с сокрытием важной информации (дело «Брейди против штата Мэриленд» 1963 г. послужило отправным пунктом для установления Верховным судом США правила, обязывающего прокуроров передавать стороне защиты любое свидетельство или улику, которое могло бы свидетельствовать в пользу обвиняемого [10]).

К обобщающе-конкретизирующим лакунам, которые по степени частотности превосходят обобщающие, но уступают конкретизирующим, можно отнести такие англо-русские соответствия, которые характеризуются одинаковым семантическим объемом, конкретизация и генерализация при этом отсутствуют. Следующие примеры демонстрируют обобщающе-конкретизирующие лакуны в рамках английских метафорических юридических терминов и их переводов на русский язык:

closed shop agreement - соглашение о найме на работу только членов профсоюза (словосочетание closed shop указывает на распространение действия соглашения исключительно на ограниченный круг лиц);

gunboat diplomacy - силовая дипломатия; дипломатия с позиции силы (здесь необходимо учитывать, что второй вариант перевода представляет собой синтаксическую трансформацию, поэтому немаловажную роль при выборе переводного соответствия будет играть строение всего предложения и место в нем данного тер- минологического сочетания);

skeleton argument - краткое изложение аргументов сторон (в данном случае дословный перевод звучит как схема аргументации, что в плане семантики тождественно предложенному более развернутому варианту перевода).

Таким образом, в рамках английской метафорической юридической терминологии и переводов терминологических единиц данной области на русский язык были обнаружены различного типа лакуны: обобщающие, конкретизирующие, обобщающе-конкретизирующие. Наиболее частотны лакуны конкретизирующего типа вследствие тенденции русского языка к более конкретному обозначению понятий по сравнению с английским языком. При этом доминирующим способом перевода является описательный перевод, который иногда служит комментарием к калькированному переводу и переводу трансформационному. Именно метод описательного перевода раскрывает в первую очередь план содержания, позволяя понять семантику термина, тогда как план выражения - форма терминологической единицы - зачастую «страдает», термин неудобен в употреблении в речи из-за объема. Такие методы перевода, как транскрипция или транслитерация и подбор лексического эквивалента, здесь не являются подходящими или вовсе не представляются возможными, поскольку внешняя форма в данном случае нисколько не будет «работать» на решение коммуникативной задачи, проблемы понимания.

В целом, анализ явления лакунарности открывает возможности для дальнейших академических изысканий и позволяет говорить о терминах права в контексте когнитивной лингвистики, корпусных исследований, теории дискурса и других научных направлений.

\section{ЛИТЕРАТУРА}

1. Байрамова Л.К. Введение в контрастивную лингвистику. Казань, 1994.

2. Махонина А.А., Стернина М.А. Типология лакун различной частеречной отнесенности // Вестник ВГУ. Серия: Филология. Журналистика. 2013. №1. С. 75-77.

3. Сорокин Ю.А., Марковина И.Ю. Опыт систематизации лингвистических и культурологических лакун: методологические и методические аспекты // Лексические единицы и организация структуры литературного текста: Сб. науч. тр. Калинин, 1983. С. 35-52.

4. Vinay J.-P., Darbelnet J. Stylistique comparée du Français et del'Anglais. Paris: Didier, 1958.

5. Law J., Martin E.A. A Dictionary of Law. Oxford, 2009.

6. Black's Law Dictionary. [Электронный ресурc]. - URL: https://www.freelawdictionary.org/

7. Macmillan Dictionary. [Электронный ресурc]. - URL: https://www.macmillandictionary.com/

8. Oxford Advanced Learner's Dictionary. [Электронный ресурс]. - URL: https://www.oxfordlearnersdictionaries.com/

9. Crosley Law. [Электронный ресурc]. - URL: https://crosleylaw.com/blog/eggshell-skull-rule-apply-texas-car-accident-cases/

10. John T. Floyd Law Firm. [Электронный ресурc]. - URL: https://www.johntfloyd.com/what-is-a-brady-violation/ 